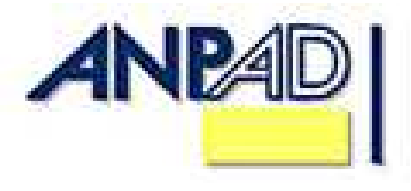

Disponível em

http://www.anpad.org.br/rac

RAC, Rio de Janeiro, v. 16, n. 5, art. 4, pp. 705-722, Set./Out. 2012

(c) EY-NC

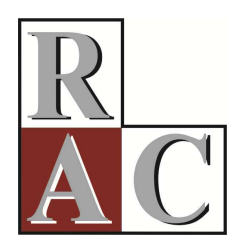

\title{
Gestão de Competências nas Relações de Trabalho: o que Pensam os Sindicalistas?
}

\section{Competence-based Management in Labor Relations: What Do the Unionists Think?}

\author{
Marcus Vinicius Gonçalves da Cruz * \\ E-mail: marcus.cruz@fjp.mg.gov.br \\ Fundação João Pinheiro - FJP \\ Belo Horizonte, MG, Brasil. \\ Amyra Moyzes Sarsur \\ E-mail: asarsur@hotmail.com \\ Fundação Pedro Leopoldo - FPL \\ Pedro Leopoldo, MG, Brasil.
}

Wilson Aparecido Costa de Amorim E-mail: wilsonamorim@bighost.com.br Universidade Municipal São Caetano do Sul - USCS

São Caetano do Sul, SP, Brasil. 


\title{
Resumo
}

O cenário macroeconômico no Brasil tem apontado para melhorias no mercado de trabalho e indicadores de emprego e renda, contexto que deveria favorecer a ação sindical. O que se observa, entretanto, é a manutenção de parâmetros tradicionais nas relações de trabalho. Este artigo objetiva analisar, sob a distinta ótica dos sindicatos, em que medida a implantação dos sistemas de gestão de competências tem sido objeto de ação sindical, tendo em vista sua adoção por boa parte das grandes organizações, e o fato de esta ser considerada uma ferramenta moderna de gestão empresarial e de pessoas. A abordagem metodológica privilegiou o enfoque qualitativo, utilizando pesquisa documental e de campo. As etapas de pesquisa constaram de: (a) levantamento bibliográfico; (b) consulta a bases de dados relacionais; (c) realização de painel de especialistas; e (d) grupo de foco. Os resultados apontam que a gestão de competências é um termo ausente nas negociações coletivas e desconhecido pelos sindicatos, reduzindo-se a ações de identificação e combate ao assédio moral e a metas abusivas, pauta central de reivindicações. Na mesma medida, o Estado não assume seu papel como agente indutor da melhoria das competências, e as organizações mantêm sua ação imperativa sobre os trabalhadores.

Palavras-chave: gestão de competências; relações de trabalho; sindicatos.

\begin{abstract}
The Brazilian macroeconomic environment has pointed to improvements in labor market, employment and income indicators, a context which should help union activity. However, traditional standards in labor relations have been maintained, especially in terms of pressures on workers to improve eligibility requirements and be accountable for results, without unions pressuring the government and organizations back. This article aims to analyze, under the distinct perspective of unions (collective representation of workers), to what extent the implementation of competence-based management systems has become a union issue, since they are considered a modern business management tool and have been adopted by many of the largest organizations. Methodology was based on a qualitative approach, using documentary and field research. Investigation steps consisted of: (a) literature review; (b) analysis of relational database; (c) expert panel; and (d) focus group. The results indicate that competence-based management is an unknown term in collective bargaining by unions, reducing their ability to identify and counter demanding and abusive goals, which is their main purpose. As such, the government doesn't assume its role of promoting skill development and organizations maintain their control over workers.
\end{abstract}

Key words: competence-based management; labor relations; unions. 


\section{Introdução}

Os países centrais vêm enfrentando reflexos da crise econômica mundial de 2008. A redução das atividades econômicas, a elevação dos déficits públicos, a pressão cambial, a concorrência de países emergentes, a diminuição das inversões públicas, o ceticismo dos cidadãos, e um contexto das relações de trabalho que aponta para o aumento do desemprego, a precarização dos vínculos de contratação e o crescimento da informalidade, tudo isso pressiona os Estados a dinamizar suas políticas de geração de emprego e renda. Tal cenário ainda é influenciado pela mobilidade dos capitais entre os países e uma nova espacialidade da produção, que se manifesta, mais evidentemente, no funcionamento dos mercados financeiros e na agilidade com que os grandes grupos empresariais internacionais se movem em busca de novos mercados de produto e trabalho. No âmbito das organizações, a competição para produção de bens e serviços com qualidade e baixo custo impele à adoção de novas tecnologias e inovações em termos de gestão.

No Brasil, o cenário macroeconômico recente mostra-se diferente desse panorama, uma vez que a expansão econômica, amparada no fluxo contínuo de entrada de capitais internacionais, ampliação da renda e elevação dos salários, apoiados no acesso ao crédito que incentivou o consumo no mercado interno, teve reflexos nas relações de trabalho com a redução do número de desempregados, $o$ aumento de trabalhadores com carteira assinada e o ganho real de salários (Amorim, 2010). No que tange às organizações, há uma competição por empregados, tanto por aqueles mais qualificados, quanto pelos de estratos mais baixos na estrutura de qualificação, para atender a uma aquecida demanda de bens e serviços do mercado. Esse cenário favorece a ação dos sindicatos em sua organização e elevação dos padrões de reivindicações. Inverte-se, desse modo, a tendência verificada nos anos de crise econômica, que persistiu até meados dos anos 2000.

Entretanto, alguns parâmetros das relações de trabalho no país se mantiveram, seja em termos do papel do Estado, marcado por uma legislação pouco flexível e intervencionista, seja pelo papel destinado ao trabalhador, no âmbito das organizações. Como exemplo, o que ocorreu na década de 1990, com a ênfase na chamada empregabilidade (Sarsur, 2010), e ampliação da cobrança por novos requisitos e qualificações do trabalhador, vem atualmente repaginado com uma nova nomenclatura, ou seja, pela via das chamadas competências. Entre um termo e outro, manteve-se a característica central das relações de trabalho de uma pressão sobre o trabalhador e de responsabilização sobre seu próprio desenvolvimento e inserção no mercado. Desta forma, empresas, governo e outras instâncias foram isentados de uma atuação corresponsável.

Tendo esse contexto como pano de fundo, este artigo $^{(1)}$ evidencia resultados de pesquisa voltada para análise das relações de trabalho e da gestão de competências, verificando as distintas visões dos sindicatos como representantes do trabalhador, foco prioritário deste estudo, tomados como dimensões de interface junto ao Estado e às organizações. A abordagem metodológica privilegiou o enfoque qualitativo, utilizando pesquisa documental e de campo. As etapas de pesquisa constaram de: (a) levantamento bibliográfico; (b) consulta a bases de dados relacionais; (c) realização de painel de especialistas; e (d) grupo de foco. Dentro desse propósito, analisou-se a perspectiva de sindicatos considerados proativos por sua postura voltada para a preservação das atividades econômicas e empregos como forma de enfrentar as dificuldades criadas pela precarização das relações de trabalho e pela modificação das atividades organizacionais (Ramalho \& Rodrigues, 2010), relacionadas ao modelo de gestão por competências em prática nas organizações do país.

\section{Competências e seu Debate}

A sociedade globalizada concretiza um modo de produção - o capitalismo - que ultrapassa fronteiras e influencia as formas de organização do trabalho e da vida social. Assim, "o caráter internacional do capitalismo, que já se prenunciava desde seus inícios, e revela-se evidente no século 
XIX, torna-se particularmente efetivo na segunda metade do século $\mathrm{XX}$, quando adquire todas as características de um modo de produção global" (Ianni, 1997, p. 145), que vai se ampliando no início do século XXI. O capitalismo mobiliza as forças produtivas (capital, tecnologia, força de trabalho, organizações, mercado etc.), desenvolvendo as relações de produção e envolvendo os padrões socioculturais, os valores e os ideais. Tal modo de produção marca os movimentos da sociedade, em níveis local, nacional e mundial. Isso, sem dúvida, deixa evidências de que a nova divisão transnacional do trabalho recria e desenvolve diferentes aspectos da questão social, dentre eles, as relações entre emprego e desemprego; o crescimento de contingentes situados na condição de subclasse; as novas formas de exploração da força de trabalho; os aspectos discriminatórios no embate com a necessidade de diversidade, bem como as crises de identidade (Bosalie, Brewster, \& Paauwe, 2009; Castells, 2003).

A recente crise econômica mundial de 2008 reforçou esses aspectos uma vez que levou a um colapso de pagamentos nos países centrais, afetando as atividades econômicas, provocando a elevação dos déficits públicos e crises financeiras e, eventualmente, políticas em alguns países como Grécia, Irlanda, Portugal, Islândia e Espanha (World Bank, 2011).

O panorama das relações de trabalho também sofreu modificações, aprofundando circunstâncias verificadas anteriormente na crise econômica nos anos 1990. Naquele momento, a crise relacionava-se com o processo de reestruturação produtiva das empresas globais e de suas cadeias produtivas, resultando no fechamento de fábricas, no aumento do desemprego e no deslocamento de investimentos produtivos para outras localidades (Clark, 2009; Guimarães, Hirata, \& Sugita, 2009; Ramalho \& Rodrigues, 2010).

A racionalização produtiva voltou-se para a obtenção de maior flexibilidade na utilização do capital e do trabalho, o que determinou novas relações nessa área. A instabilidade dos mercados e o acirramento da concorrência começaram a exigir das empresas uma flexibilidade produtiva compatível com as demandas impostas (Beck, 2010). As organizações passaram a demandar maior autonomia no uso da força de trabalho, tanto durante as negociações coletivas como junto ao Estado, reivindicando menores restrições legais e políticas na administração de pessoal, além de maior qualificação da mão de obra. A fim de adaptarem-se aos novos tempos, essas organizações começaram a implantar processos de reengenharia, flexibilização da produção, redesenho de estruturas, terceirização de atividades, dentre outros aspectos, como formas de sobrevivência e manutenção de atividades que permitissem a perpetuação da obtenção de lucros e a minimização de custos e riscos (Bresciani, 1997; Chesnais, 1996; Gorz, 1995; Kurz, 1997; Leite, 2003; Singer, 1996).

No caso brasileiro, a superação da crise internacional de 2008 propiciou um crescimento da economia nacional, em um processo que se sobrepôs à valorização da moeda, ao aumento dos gastos do governo, à elevação da carga tributária e ao crescimento das importações. A elevação do produto interno bruto, somada à ampliação do crédito, propiciou um aumento da massa salarial, provocando um aquecimento do mercado interno e uma diminuição do desemprego e da informalidade no mercado de trabalho (Amorim, 2010).

A superação da retração econômica produziu efeitos interessantes sobre as relações de trabalho, uma vez que afetou diretamente as negociações coletivas, conforme descreve Amorim (2010). De um lado, no topo da estrutura sindical, as centrais sindicais chamaram para si a responsabilidade de articular movimentos unitários que buscassem pressionar o governo para tomar medidas que atenuassem a crise, seja em termos macroeconômicos (pressões por redução de juros), setoriais (medidas de proteção e/ou estímulo a segmentos produtivos), seja em termos de mercado de trabalho (flexibilização da legislação trabalhista ou alteração no seguro desemprego, por exemplo). Na base da estrutura sindical, os sindicatos buscaram acionar os mecanismos de mobilização para propor alternativas político-institucionais em âmbito regional, com o objetivo de proteger e estimular a criação de empregos e enfrentar os efeitos sociais das demissões de trabalhadores, seguindo a lógica convencional da ação sindical brasileira (Nabuco \& Carvalho, 1999; Rodrigues, 1979). No entanto, os processos de negociação coletiva visaram principalmente à recuperação salarial, buscando superar os patamares inflacionários. Essa evolução, ao longo dos últimos anos, pode ser verificada na Tabela 1. 
Tabela 1

Indicadores Econômicos e Distribuição dos Reajustes Salariais em Comparação com o INPCIBGE - Brasil - 2000 a 2010 (\%)

\begin{tabular}{|c|c|c|c|c|c|c|c|c|c|c|c|}
\hline Indicadores & 2000 & 2001 & 2002 & 2003 & 2004 & 2005 & 2006 & 2007 & 2008 & 2009 & 2010 \\
\hline $\begin{array}{l}\text { Variação } \\
\text { PIB }\end{array}$ & 4,30 & 1,30 & 2,70 & 1,20 & 5,70 & 3,20 & 4,00 & 6,10 & 5,10 & $-0,20$ & 7,45 \\
\hline $\begin{array}{l}\text { Taxa Média } \\
\text { Anual de } \\
\text { Desemprego } \\
\text { (1) }\end{array}$ & 17,60 & 17,60 & 19,00 & 19,90 & 18,70 & 16,90 & 15,80 & 14,80 & 13,40 & 13,80 & 11,90 \\
\hline $\begin{array}{l}\text { Reajuste } \\
\text { acima do } \\
\text { INPC }\end{array}$ & 52,27 & 45,37 & 22,66 & 19,60 & 54,70 & 71,70 & 87,90 & 87,70 & 88,00 & 78,90 & 88,70 \\
\hline $\begin{array}{l}\text { Reajuste } \\
\text { igual ao } \\
\text { INPC }\end{array}$ & 14,93 & 18,71 & 27,05 & 22,70 & 26,10 & 16,30 & 8,80 & 8,30 & 10,50 & 12,70 & 4,30 \\
\hline $\begin{array}{l}\text { Reajuste } \\
\text { abaixo do } \\
\text { INPC }\end{array}$ & 32,80 & 35,92 & 45,29 & 57,70 & 19,10 & 12,00 & 3,30 & 4,00 & 11,90 & 7,40 & 3,10 \\
\hline $\begin{array}{l}\text { Total de } \\
\text { acordos }\end{array}$ & 375 & 529 & 499 & 556 & 658 & 640 & 656 & 715 & 706 & 692 & 700 \\
\hline
\end{tabular}

Nota. Fonte: Departamento Intersindical de Estatística e Estudos Socioeconômicos. (2010). Balanço das negociações dos reajustes salariais em 2010 (Estudos \& Pesquisas No 55). São Paulo, SP: Autor.

A partir das transformações no mundo do trabalho, Souza e Carvalho (2009) reforçam que a ideia disseminada no mercado, de forma geral, é a de que o trabalhador deve adaptar-se às mudanças nos processos produtivos para manter-se ativo. Para Santos (2004), o modelo de educação tayloristafordista estava eivado de um caráter tecnicista pelo seu foco na profissão. Este modelo orientava-se para a qualificação operacional adequada àquela forma de organização técnica do trabalho, enquanto, nos modelos contemporâneos pós-fordistas de educação profissional, o trabalhador vende-se no mercado por suas competências. Para isso, adota-se um perfil profissional em que o indivíduo deve: desenvolver múltiplas habilidades necessárias à realização de diversas tarefas; utilizar da criatividade e iniciativa para solução de problemas; desenvolver capacidade para o trabalho em grupo que envolva gestão de processos e comunicação; estar apto para identificar as causas dos problemas; assumir responsabilidades e aderir aos projetos da empresa; alçar-se a nível elevado de escolaridade; e buscar permanente (re)qualificação (Veloso, 2002). Sarsur (2010) comenta que fica difícil se desvencilhar dessas ideias que vão sendo inculcadas de modo a reforçar a chamada empregabilidade do trabalhador, e no seu bojo, a noção de competências.

Nesse sentido, os modelos de gestão de competências implantados nas organizações necessitam se adequar à realidade das mesmas, já que, na maioria das vezes, vêm sendo adotados à revelia das características do corpo funcional, dos valores empresariais ou dos recursos dos quais a instituição dispõe para alcance de resultados (Sarsur, 2010), ainda que haja uma consolidação teórica (Bitencourt \& Barbosa, 2010) a partir de autores brasileiros, como Ruas, Ghedine, Dutra, Becker e Dias (2005), Fischer (2001), Ruas (2005) e Dutra (2004).

Em uma vertente mais crítica, Ribeiro e Santos (2008) afirmam que os conceitos de competência propagam a exigência de maior escolaridade, mas diz considerar, na avaliação da força de trabalho, as competências, não a qualificação. Esses conceitos difundem a necessidade de competências, mas as novas formas de trabalho não exigem necessariamente, nem maior qualificação, nem maior competência. Os mesmos divulgam amplamente que o novo trabalhador deverá ser capaz 
de lidar com os eventos deflagradores das competências, definidos essencialmente por seu caráter de imprevisibilidade e criatividade no trato. Entretanto, as organizações, investem recursos inestimáveis no controle e na padronização das ocorrências do trabalho. As empresas afirmam formalmente a valorização das competências que pertencem à esfera privada do indivíduo, mas perseguem incansavelmente formas cada vez mais elaboradas de objetivar, expropriar e padronizar o conhecimento tácito. O paradoxo da complexificação do trabalhador coletivo e da simplificação e esvaziamento do trabalhador individual é gerado nesse processo. Isso porque o trabalhador, ao ser descartado, não deixa marcas pessoais, pois seu valor já foi agregado à mercadoria e ao processo coletivo de trabalho.

Em uma perspectiva interessante sobre esse paradoxo, Kaufman (2010) analisa a gestão de recursos humanos das organizações segundo três tipos dispostos em uma pirâmide. Na base da pirâmide, no tipo mais frequente, existe um conjunto numeroso de empresas cujas políticas e práticas de recursos humanos são mais tradicionais, próprias de modelos de corte fordista. O segundo tipo com um número menor de empresas - apresenta um conjunto um pouco mais desenvolvido de políticas e práticas de recursos humanos, nas quais ainda permanecem presentes relações conflitivas, mas também são estimuladas relações cooperativas em busca de melhores resultados. Nessas empresas, o trabalho, em tese, seria mais atrativo para os empregados, em comparação com o primeiro grupo. No terceiro grupo, no topo da pirâmide, estariam as melhores empresas para trabalhar, com práticas sofisticadas de recursos humanos, com estímulo permanente ao comprometimento e engajamento no trabalho em equipe. Pelos critérios de Kaufman (2010), a condução da gestão por competências aqui referida encontra-se no limiar entre o primeiro e o segundo grupo de empresas.

Outra importante reflexão é oferecida por Brewster (2007) que, ao comparar a gestão de recursos humanos nos EUA e na Europa, identifica quatro aspectos nos quais os respectivos modelos se diferenciam. O primeiro deles, de caráter cultural, seria o individualismo - mais presente nos EUA que na Europa. Um segundo aspecto seria o papel do Estado - patrocinador de uma regulação mais ativa do trabalho na Europa e menos nos EUA. Um terceiro elemento seria a maior influência sindical e o nível de participação dos trabalhadores nas questões laborais, maior na Europa e menor nos EUA. O quarto aspecto seria o padrão da propriedade das empresas que exerceria menos pressão por lucros de curto prazo na Europa comparativamente aos EUA. Pfeffer (2007) corrobora tal visão afirmando, com base em suas pesquisas, que a insatisfação com o emprego e o desengajamento têm se tornado características cada vez mais comuns nos Estados Unidos, com prejuízos para empregados e empresas.

Bosalie, Brewster e Paauwe (2009) ratificam que o modelo americano de gestão de recursos humanos, com excessiva ênfase em estratégia e resultados, a partir de estímulos individuais e desempenho do trabalhador, ignora aspectos situacionais e subjetivos, incidindo no risco de adoção de uma perspectiva engenheira para um assunto - relações de trabalho - que é do campo das relações humanas (Kaufman, 2010).

Esta é uma preocupação já apontada nos estudos seminais de Zarifian (2001), quando alerta que a concepção tradicional de competências apega-se a uma análise objetiva dos postos de trabalho, numa perspectiva taylorista e burocrática do trabalhador nas organizações, ignorando as potencialidades do indivíduo. De outra parte, a análise de Fleury e Sarsur (2007) salienta a ausência do ganho para o trabalhador nessa concepção. Dessa forma, confirma-se que a ideia de competências deve ser ampliada ao envolver o indivíduo por completo, nos termos de Morin (2001).

Quanto ao papel do Estado, identificado por Brewster (2007), no caso brasileiro este age de modo rarefeito quanto às competências, seja na direção de consolidar políticas públicas de educação profissional, seja na de engendrar processos de certificação ocupacional, ocorrendo, do lado da demanda, a partir dos cursos oferecidos pelas entidades do Sistema $\mathrm{S}$ (SESC/SENAC/SENAI/SENAT/SENAR), ou, ainda, em iniciativas de alguns entes federativos brasileiros, como São Paulo, Minas Gerais e Bahia. Projetos desenvolvidos a partir das entidades ligadas aos trabalhadores também são escassos, com discussões voltadas, em sua maioria, para o 
escopo de formação profissional, no contexto da educação dos trabalhadores (Sarsur, Fischer, \& Amorim, 2008).

A importância da atuação de outros atores no processo de desencadeamento das competências pode ser verificada no amplo trabalho de pesquisa de Barreto et al. (2010), junto a gestores empresariais da área de Recursos Humanos. Esses profissionais apontam, dentre as políticas e práticas vistas como mais relevantes no futuro, a educação, o treinamento e a qualificação da força de trabalho, o que reforça a importância de ações voltadas para a formação profissional em uma articulação com múltiplas instituições, inclusive aquelas capitaneadas pela ação sindical.

\section{Posições Metodológicas}

A pesquisa realizada tem como escopo geral a análise de como a gestão de competências em sua vertente organizacional está afetando as relações de trabalho no Brasil nos planos individual (trabalhador) e coletivo (sindicato), em um contexto de transformação do mundo do trabalho. Assim sendo, optou-se pela abordagem de pesquisa qualitativa. As pesquisas qualitativas seguem a tradição compreensiva ou interpretativa, isto é, relacionam-se às crenças, percepções, sentimentos e valores, e que seu comportamento tem sempre um sentido, um significado que não se dá a conhecer de modo imediato, precisando ser desvelado (Alves-Mazzotti \& Gewandsznajder, 1999). Essa opção metodológica também se mostrou adequada uma vez que, para entendimento do fenômeno das competências, verificou-se a coexistência de diversas variáveis interagindo concomitantemente (Lüdke \& André, 1986). Assim, a análise busca verificar e analisar diferentes variáveis que, eventualmente, estejam relacionadas ao modelo de gestão de competências do ponto de vista das relações entre estes distintos atores - Estado, sindicato, empresa e trabalhadores.

Nos termos da pesquisa foram realizados os seguintes procedimentos metodológicos.

\section{Etapa I: levantamento bibliográfico}

Para o levantamento de trabalhos acadêmicos relacionados ao tema Gestão de Competências na perspectiva dos sindicatos, foram realizadas consultas por meio de ferramentas de busca a bases de dados eletrônicas - SciELO (Scientific Library on Line) e Qualis dos Periódicos CAPES, bem como suas teses e dissertações. Para um melhor panorama da produção científica na área, fez-se uma consulta ao sítio eletrônico da Associação Nacional de Pós-Graduação e Pesquisa em Administração (ANPAD). Autores como Russo, Macedo-Soares e Villas (2006) reforçam a importância desses levantamentos, uma vez que, no Brasil, o Qualis, criado pela Coordenação de Aperfeiçoamento de Pessoal de Nível Superior (CAPES) hierarquiza os periódicos científicos nacionais e internacionais e os qualifica em categorias indicativas de qualidade. Da mesma forma, o SciELO se propõe à disseminação da produção científica em formato eletrônico, enquanto a ANPAD é a instituição que concentra a vanguarda na publicação da produção na área de Administração no país.

Dos artigos Qualis, foram selecionados, para o nível internacional, os periódicos classificados nos estratos A1 e A2. Já para o nível nacional, verificaram-se ainda os estratos B1, B2 e B3, para ampliação da pesquisa. A partir da seleção dos periódicos, utilizaram-se as palavras-chave como critério de busca de artigos (Barreto et al., 2010) e a busca integral em todas as edições para verificar a existência de correlatos relativos aos termos competência e sindicato. A busca por palavras-chave foi realizada nos periódicos investigando o período disponível na consulta, uma vez que a limitação de tempo não se mostrou conveniente para tema recente e de articulação relativamente restrita. As palavras-chave utilizadas foram competência/competence (inglês)/competencia (espanhol), permitindo o vínculo a outra palavra existente. Não houve resultado para as traduções da palavra sindicato/union (inglês)/unión (espanhol). 
Após a realização da busca por meio da palavra-chave, os achados tinham, primeiramente, seus títulos analisados e, em seguida, seu resumo lido. No caso do título indicar que o artigo tratava sobre gestão de competências, a leitura do resumo era realizada, para verificar se o objetivo realmente envolvia a análise das competências. Essa seleção considerou artigos, dissertações e teses sobre competências e possíveis articulações com as relações de trabalho, temática importante ao envolver as estratégias de competências. A Tabela 2 descreve a produção no Qualis da CAPES.

Tabela 2

\section{Periódicos Avaliados pelo Qualis e Produção Selecionada}

\begin{tabular}{|c|c|c|}
\hline Titulo do Periódico & Estrato Qualis & Produção \\
\hline Academy of Management Journal & A1 & 2 \\
\hline Expert Systems with Applications & A1 & 4 \\
\hline Human Relations (New York) & A1 & 4 \\
\hline International Business Review & A1 & 2 \\
\hline International Journal of Behavioral Development (Print) & A1 & 2 \\
\hline International Journal of Human Resource Management & A1 & 8 \\
\hline International Journal of Information Management & A1 & 1 \\
\hline International Journal of Production Economics & A1 & 1 \\
\hline Journal of International Management & A1 & 4 \\
\hline BAR. Brazilian Administration Review & A2 & 1 \\
\hline Business Strategy and the Environment & A2 & 1 \\
\hline Career Development International & A2 & 2 \\
\hline Ciência \& Saúde Coletiva (Online) & $\mathrm{A} 2$ & 1 \\
\hline Ciência da Informação (Impresso) & A2 & 2 \\
\hline Construction Management \& Economics (Print) & A2 & 2 \\
\hline International Journal of Entrepreneurship and Innovation Management (Online) & A2 & 2 \\
\hline Journal of Knowledge Management & A2 & 6 \\
\hline Latin American Business Review (Binghamton, N.Y.) & A2 & 1 \\
\hline Learning Organization & A2 & 3 \\
\hline Management Decision & A2 & 4 \\
\hline Revista de Administração Pública (Impresso) & A2 & 5 \\
\hline Management Research News & B1 & 4 \\
\hline Perspectivas em Ciência da Informação (Impresso) & B1 & 3 \\
\hline Pró-Posições (UNICAMP. Impresso) & B1 & 2 \\
\hline RAC Eletrônica & B1 & 5 \\
\hline RAM. Revista de Administração Mackenzie (Impresso) & B1 & 5 \\
\hline Revista Gaúcha de Enfermagem (UFRGS. Impresso) & B1 & 2 \\
\hline Revista Latino-Americana de Enfermagem (Online) & B1 & 3 \\
\hline Texto \& Contexto Enfermagem (UFSC. Impresso) & B1 & 2 \\
\hline
\end{tabular}


Tabela 2 (continuação)

\begin{tabular}{lcc}
\hline \multicolumn{1}{c}{ Titulo do Periódico } & Estrato Qualis & Produção \\
\hline Ambiente Construído (Online) & B2 & 1 \\
Base (UNISINOS) & B2 & 2 \\
BBR. Brazilian Business Review (Edição em português. Online) & $\mathrm{B} 2$ & 1 \\
Journal of Education for Business & $\mathrm{B} 2$ & 1 \\
Project Management Journal & $\mathrm{B} 2$ & 7 \\
REAd. Revista Eletrônica de Administração (Porto Alegre. Online) & $\mathrm{B} 2$ & 2 \\
Revista Brasileira de Orientação Profissional & $\mathrm{B} 2$ & 1 \\
Revista Eletrônica de Enfermagem & $\mathrm{B} 2$ & 2 \\
Revista Interface & $\mathrm{B} 2$ & 1 \\
Alcance (UNIVALI) (Cessou em 2007) & $\mathrm{B} 3$ & 2 \\
REGE. Revista de Gestão USP & $\mathrm{B} 3$ & 2 \\
Desenvolvimento em Questão & $\mathrm{B} 3$ & 1 \\
Faces : Revista de Administração (Belo Horizonte. Impresso) & $\mathrm{B} 3$ & 1 \\
Revista Brasileira de Gestão de Negócios (Online) & $\mathrm{B} 3$ & 2 \\
\hline
\end{tabular}

Nota. Fonte: Dados da pesquisa.

Foram identificados 244 documentos que tratam do assunto, entre artigos, dissertações e teses, sendo 35 artigos da ANPAD, dos quais 32 foram publicados em eventos e três em periódicos, enquanto identificaram-se 114 classificados no Qualis da CAPES, além de 19 teses/dissertações selecionadas pela CAPES. Na consulta à base de dados SciELO, foram identificadas 171 chamadas e selecionados 5 artigos que não constavam das consultas anteriores. Não foram encontradas associações entre competências e sindicatos, circunstância que será analisada posteriormente.

\section{Etapa II: levantamento em bases de dados relacionais}

A análise de bancos de dados relacionais sobre o tema indica a abrangência da gestão de competências sob as perspectivas organizacional e sindical. A ideia de buscar a análise pela via organizacional se justifica por ser a vertente corrente no caso brasileiro e por propiciar uma dimensão do escopo das competências no estrato organizacional. O levantamento foi realizado com respeito às práticas empresariais vinculadas à gestão por competências (captação, retenção, educação corporativa, remuneração), obtidas a partir de consultas a Pesquisa Melhores Empresas para se Trabalhar e Delphi 2010 - ambas realizadas pelo Programa de Estudos em Gestão de Pessoas (PROGEP) da Fundação Instituto de Administração (FIA). Foram realizados levantamentos buscando-se dados e informações de 468 empresas que, em 2010, participaram voluntariamente de uma pesquisa que levantou aspectos relacionados ao clima organizacional e a características da gestão de recursos humanos, e, nesse caso específico, à adoção de programas educacionais para empregados, programas esses concebidos com base na identificação de competências críticas. A Tabela 3 apresenta dados pertencentes à pesquisa das Melhores Empresas para se Trabalhar no Brasil (Programa de Estudos em Gestão de Pessoas [PROGEP] e Fundação Instituto de Administração [FIA], 2010). 
Tabela 3

Empresas que Possuem Ações e Programas Educacionais Concebidos com base na Identificação das Competências Críticas (Empresariais e Humanas)

\begin{tabular}{|c|c|c|c|c|c|c|c|c|}
\hline \multirow{3}{*}{ Funções } & \multirow{2}{*}{\multicolumn{2}{|c|}{$\begin{array}{l}\text { Empresa Não } \\
\text { Adota Educação } \\
\text { Corporativa }\end{array}$}} & \multicolumn{4}{|c|}{ Empresa Adota Educação Corporativa } & \multirow{2}{*}{\multicolumn{2}{|c|}{ Total }} \\
\hline & & & \multicolumn{2}{|c|}{$\begin{array}{l}\text { Não identificam } \\
\text { competências }\end{array}$} & \multicolumn{2}{|c|}{$\begin{array}{c}\text { Identificam } \\
\text { competências }\end{array}$} & & \\
\hline & $\mathbf{N}^{\mathbf{o}}$ & $\%$ & $\mathbf{N}^{\mathbf{o}}$ & $\%$ & $\mathbf{N}^{\mathbf{o}}$ & $\%$ & $\mathbf{N}^{\mathbf{o}}$ & $\%$ \\
\hline Diretores & 50 & 11 & 68 & 15 & 350 & 75 & 468 & 100 \\
\hline Gerentes & 50 & 11 & 37 & 8 & 381 & 81 & 468 & 100 \\
\hline $\begin{array}{l}\text { Demais } \\
\text { empregados }\end{array}$ & 50 & 11 & 40 & 9 & 378 & 81 & 468 & 100 \\
\hline
\end{tabular}

Nota. Fonte: elaborado pelos autores a partir de Programa de Estudos em Gestão de Pessoas e Fundação Instituto de Administração. (2010). Melhores empresas para se trabalhar - Relatório de Benchmarking (p. 52). São Paulo: Autor.

Os resultados apurados revelam que 75\% das empresas participantes identificam competências críticas como base para o desenvolvimento de programas de treinamento e educação para seus diretores. Da mesma forma, em $81 \%$ das empresas a identificação de competências é adotada tanto para níveis de gerência quanto para os demais empregados, praticamente na mesma proporção de organizações.

Esses dados estão longe de serem conclusivos a respeito da disseminação da adoção da prática da gestão por competências, mas indicam que, para este conjunto de organizações, cerca de um milhão de trabalhadores de alguma forma foram alcançados por uma das aplicações do modelo (PROGEP, FIA, 2010). Embora não tenham sido encontradas informações para a utilização das competências no que se refere às outras políticas e aos outros processos de recursos humanos, estima-se que a utilização isolada ou não das competências também seja razoável. A grande atividade das consultorias especializadas e as declarações de gerentes também em publicações especializadas voltadas ao público profissional reforçam esta hipótese.

O levantamento no banco de dados do Departamento Intersindical de Estatística e Estudos Socioeconômicos (DIEESE), em São Paulo, por meio do Sistema de Acompanhamento de Contratos Coletivos (SACC Brasil), indicou preliminarmente que a gestão por competência é um termo praticamente ausente nas negociações coletivas brasileiras. A pesquisa seguiu a metodologia de classificação das cláusulas dos contratos coletivos no país, que permite o resgate de cláusulas específicas segundo os conteúdos de: (a) salário e remuneração; (b) condições de trabalho; (c) relações de trabalho; (d) relações sindicais; (e) gestão/participação; e (f) normas específicas de profissões; e não encontrou o tema em discussão pelos sindicatos. A palavra competências como variável de busca/pesquisa sequer existe, conforme levantamento realizado no mesmo para fins desta pesquisa. Cabe ressaltar que este banco de dados possui o conjunto de acordos e convenções coletivas daqueles sindicatos vinculados ao DIEESE em todo o país. A busca por palavra-chave competência não revelou nenhum tipo de registro em todo o sistema, logo, a temática ainda está longe de despertar atenção à representação coletiva de trabalhadores no país.

\section{Etapa III: painel de especialistas}

O trabalho de pesquisa de campo definiu a análise da gestão por competências em dois setores dinâmicos do sindicalismo brasileiro, que também são referência em termos da estruturação das organizações e do modelo de gestão de competências. Para tanto, foram escolhidos como segmentos para verificação, o setor bancário e o setor metalúrgico, de Belo Horizonte (Minas Gerais) e São Paulo 
(São Paulo), por meio do método de painel de especialistas que permite realizar inferências sobre relações causais a partir de observações de um objeto de estudo durante certo período de tempo (Bruyne, 1991).

A escolha do setor bancário justifica-se pelo cenário estrutural vigente no sistema financeiro nacional do Brasil desde o Plano Real, nos idos de 1994. A partir de diretrizes do Governo Federal, houve redução na quantidade de bancos estaduais e bancos privados nacionais, e o surgimento, com rápida evolução na participação de mercado, das instituições financeiras estrangeiras. Em função dessas mudanças, as organizações bancárias atuantes no mercado brasileiro passaram por um processo de reestruturação cuja base era o aumento da eficiência para melhorar sua competitividade, o aprimoramento de seus produtos e serviços e a diminuição dos custos para os clientes, com o objetivo de fidelizá-los. As turbulências enfrentadas recentemente pelo setor financeiro global vêm apresentando ações distintas das instituições financeiras. No caso brasileiro, o impacto dessa situação foi minimizado pelas medidas de acompanhamento da autoridade monetária; no entanto, com grande perda de postos de trabalho bancário. Nesse contexto de mudança, várias instituições bancárias adotaram modelos de gestão por competências, enquanto, do ponto de vista sindical, há crescentes dificuldades para o desenvolvimento da ação coletiva e tendência de que prevaleçam ações mais segmentadas (Krein \& Gonçalves, 2006).

No setor siderúrgico, área marcada por um sindicalismo combativo, a adoção da gestão por competências advém da necessidade de fazer frente ao aumento da competitividade e do desenvolvimento do negócio, geralmente inserido em mercado caracterizado pela turbulência e pela alta competitividade em nível global (Barbosa, 2002).

O painel de especialistas se enquadrou na pesquisa com enfoque qualitativo, e utilizou de amostragem não probabilística por tipicidade, isto é, foram escolhidos, como sujeitos da pesquisa, aqueles profissionais representativos do universo total de componentes do sistema (Vergara, 1998). Em pesquisa com enfoque qualitativo, não é exigido um número grande de sujeitos, pois esse número varia de acordo com o foco da pesquisa (Alves-Mazzotti \& Gewandsznajder, 1999).

Assim também se justifica a opção pelo painel de especialistas enquanto modo de investigação, pois isso permite a um grupo de indivíduos debater sobre determinada problemática e delinear um entendimento geral sobre o assunto ou sua tendência no futuro (Flick, 2004). Realizou-se uma plenária com oito especialistas na área de relações de trabalho no mês de maio de 2010, explanando-se inicialmente as distintas vertentes da gestão por competências, enfatizando-se a perspectiva do Estado quanto à dimensão da certificação destas; e a perspectiva sindical, tendo a competência como formação profissional e de classe. Em seguida, foram lançados questionamentos com foco em duas vertentes teóricas específicas: (a) a experiência de implantação da gestão por competências nas empresas - especialmente no setor bancário e no ramo metal-mecânico; e (b) as experiências de negociação envolvendo sindicatos.

Da discussão, foram consolidadas hipóteses de pesquisa a serem aplicadas em uma etapa posterior, organizada em forma de grupos de foco, a observar:

- Gestão por competências não se aplica ao chão da fábrica;

- Gestão por competências é modismo e por isso não é discutida pelos sindicatos;

Gestão por competências é uma discussão de ganhos individuais e não cabe ao sindicato, que tem por prioridade a discussão de conteúdos coletivos;

Sindicatos entenderam, em dado momento, que sua função de apoio ao desenvolvimento do trabalhador resumia-se ao FAT, e não se atualizaram, deixando de perceber a importância da gestão por competências;

Sindicatos não têm domínio teórico da abordagem e, por isso, não discutem o tema; 
Sindicatos chamam a gestão por competências com outra nomenclatura (tais como assédio moral e qualificação), que julgam ser a mesma coisa.

Após este estágio da pesquisa, foram realizados dois grupos de foco (Collis \& Hussey, 2005), com membros da área sindical em São Paulo e em Belo Horizonte, para levantamento do estado geral das ações empreendidas na área de gestão de competências.

\section{Etapa IV: grupo de foco}

Os grupos de foco são utilizados para coligir dados relativos a impressões e opiniões de um grupo de pessoas que está envolvido em uma situação comum (Collis \& Hussey, 2005). Em julho de 2010, reuniram-se em São Paulo doze representantes de diversos sindicatos de trabalhadores bancários, para discutir a gestão de competências nas organizações bancárias. Na reunião foram apresentadas distintas perspectivas sob o ponto de vista do Estado, sindicatos, empresas e trabalhadores. As percepções foram registradas e analisadas sob o ponto de vista de como a gestão por competências compõe o repertório desses atores. O intuito foi coligir tais percepções segundo as premissas recomendadas na literatura. Em Belo Horizonte, o grupo de foco composto por sindicalistas representantes da área metal-mecânica foi realizado em agosto de 2010, com a presença de sete sindicalistas. Ambos os grupos tiveram reuniões de aproximadamente quatro horas de duração, e as informações foram integralmente registradas para posterior análise.

As premissas recomendadas por Collis e Hussey (2005) foram utilizadas por meio da reunião de indivíduos experientes, que previamente sabiam dos objetivos do estudo, com o moderador atuando para dirimir dúvidas e esclarecer os conceitos para os participantes, por meio de linguagem própria do contexto local. Aos componentes do grupo, deixou-se que discutissem entre si os tópicos apresentados, com intervenções pontuais do moderador de modo que a contribuição de todos fosse possível. Todas as hipóteses apresentadas foram discutidas e, da mesma forma, todas as intervenções foram registradas pelos três pesquisadores que atuavam como observadores.

O desenvolvimento da pesquisa teve continuidade com consultas aos sindicatos até o início do segundo semestre de 2010. A ação dos pesquisadores limitou-se a este período por conta da indisponibilidade de agenda dos dirigentes sindicais, que sinalizaram seu envolvimento com as eleições gerais de outubro daquele ano. Ao longo de 2011, os pesquisadores participaram de um seminário no qual os dirigentes sindicais e patronais da área bancária discutiram aspectos relacionados às políticas e às práticas de remuneração (maio) e também do evento nacional no qual os sindicatos bancários definiram suas posições para a campanha salarial deste ano (julho). Entre setembro e outubro de 2011 também foram realizadas reuniões devolutivas junto aos especialistas em Belo Horizonte e São Paulo, respectivamente. Ao final do ano, as articulações com os sindicalistas e o sindicato patronal apontaram para a continuidade da pesquisa.

\section{Posições Analíticas}

Os achados de pesquisa indicaram que o levantamento bibliográfico apontou poucas obras voltadas para uma análise aprofundada da ação sindical sob a perspectiva da gestão por competências. A atuação do Estado tem sido desenvolvida na literatura a partir da descrição e da análise de programas voltados para a educação profissional, em sua maioria envolvendo uma gama maior de atores, enquanto a maior parte da literatura volta-se para a gestão das competências nas organizações, observando o papel dos indivíduos nesse contexto.

De um ponto de vista geral, o levantamento bibliográfico indica as competências como eixo em torno do qual a política de gestão de recursos humanos se alinha às competências essenciais e, por extensão, à orientação estratégica da organização. Dessa forma, o referencial de competências alcança grande parte das políticas e processos de recursos humanos, tais como seleção, atração e retenção de 
talentos, treinamento e desenvolvimento, educação corporativa, planos de cargos e salários, avaliação, programas voltados às carreiras, e, claro, remuneração. Assim, um primeiro aspecto analítico é a dificuldade de mensuração da real proporção da adoção do modelo de gestão por competências nas organizações.

Outro aspecto revelado é que, no caso brasileiro, e em especial no campo estudado, não há envolvimento dos trabalhadores de todos os níveis organizacionais nos programas de competência na maioria das organizações. Isso reforça os princípios tayloristas-fordistas de separação entre concepção e execução, que propiciam um viés crítico da questão das competências na linha de Ribeiro e Santos (2008). Se uma das tendências mais propaladas nas odes organizacionais relaciona-se à necessidade de uma mão de obra apta a preencher as lacunas existentes em termos educacionais diante dos novos processos de gestão e de cunho tecnológico adotados pelas organizações (Souza \& Carvalho, 2009), parece contraditória a não inserção dos trabalhadores nos processos de gestão por competências.

A análise de bancos de dados relacionais sobre o tema indica a abrangência da gestão de competências sob a perspectiva organizacional, como já havia sido verificado na literatura. De modo geral, a gestão de competências está relacionada com as ações de Gestão de Pessoas em grande parte das organizações brasileiras. Concentram-se nos estratos superiores da organização, com pouca participação de trabalhadores dos níveis mais baixos da estrutura organizacional. Entretanto, não há referências quanto à participação dos sindicatos. Reforçando essa contradição, no campo das negociações coletivas, praticamente não há evidências de que a gestão por competências, ao menos com esse nome, faça parte de acordos coletivos.

Esse aspecto reforça a proposição de Sarsur, Fischer e Amorim (2008), que, ao verificarem pouco conhecimento do tema por parte dos sindicatos, tangenciando a omissão quanto à sua participação, deixam de lado os seus representados, os trabalhadores, nos processos de implantação dos modelos de competências nas empresas. Os autores sugerem que, dessa forma, os trabalhadores passem a ser conduzidos ao processo sem o devido acompanhamento da representação sindical, o que poderia pressupor uma aceitação, mas não efetivos envolvimento e satisfação com a adoção dos modelos, sua dinâmica de funcionamento e resultados. Por outro lado, esta dinâmica também não é acompanhada pelo Estado.

Reforçando essa constatação, no painel com especialistas, estes apontaram que o termo competências tem sido bastante difundido no contexto empresarial, sendo uma tecnologia de gestão que permeia as organizações, ainda que não seja ainda o foco principal de referência da classe trabalhadora no contexto coletivo.

Tais circunstâncias vão ser reforçadas pelos resultados dos painéis de especialistas, tanto no caso mineiro quanto no caso paulista, uma vez que permanece desconhecido o significado da gestão de competências entre os dirigentes e assessores técnicos dos sindicatos, não sendo utilizado no repertório dos mesmos.

Mantendo-se as premissas metodológicas e da literatura foram descritas situações relacionadas à adoção do modelo de competências nas organizações aos atores que estavam ligados diretamente às relações de trabalho do lado sindical. Após esta apresentação, alguns dos participantes chegaram a estabelecer alguma conexão entre o modelo de competências e as ações de gestão de pessoas das empresas no nível dos indivíduos. Essas ações, geralmente são ligadas à análise de desempenho e resultados, bem como a partir do fenômeno do assédio moral. Nesses casos, a porta de entrada para o termo competências se configura na pressão criada pelo estabelecimento de metas dentro das políticas de remuneração variável que o modelo comporta. Essa iniciativa vem sendo incorporada não apenas no âmbito das organizações privadas, mas também por instituições do setor público, no contexto do discurso brasileiro da modernização do Estado.

De outra parte, ainda que no campo mais direto das negociações coletivas, as competências não estejam presentes, de maneira indireta, no meio sindical, foram constatadas iniciativas que, de certa forma, retomam discussões dos anos 1990 no campo institucional mais amplo das ações de 
qualificação profissional. Nos contatos com os atores sindicais, verificou-se a mobilização pela criação de escolas de nível superior por parte do Sindicato dos Bancários de São Paulo e também pelo DIEESE, órgão de assessoria e pesquisa dos sindicatos brasileiros, o que se insere em uma das vertentes da gestão voltada para competências, e por outro lado reforça a lacuna deixada pelo Estado em termos de educação profissional.

Os achados, quanto à ação sindical, encontram respaldo em Sarsur et al. (2008), que sugerem que o(s) modelo(s) de competências praticados pelas organizações em sua gestão de pessoas poderiam caracterizar-se por uma resistência à interlocução com os trabalhadores e suas formas de representação. No entanto, em termos gerais, as discussões por parte dos sindicatos ainda estão centradas na recuperação dos patamares remuneratórios e na manutenção dos postos de trabalho, além de uma inserção mais adequada em termos das relações de trabalho, aproveitando do panorama de certa forma favorável aos trabalhadores.

$\mathrm{Na}$ pesquisa sobre gestão de competências, verificou-se que, se de um lado o trabalho permanece como uma categoria central para o mercado capitalista e seu posicionamento como ser social (indo além da esfera profissional), de outro este continua sujeito a formas mais elaboradas de controle da força de trabalho. Ao exacerbar a valorização de uma identidade reforçada individualmente, principalmente com os esquemas de controle voltados para a prevalência da necessidade de cumprir metas, mantém-se o nível de conflito latente por meio do incentivo à competição entre os membros da organização. Assim, o sistema de gestão de competências distancia o trabalhador de sua identidade coletiva, conforme alertado por Antunes e Alves (2004), e Antunes (2006) para os novos processos de gestão organizacionais.

Este achado pode ser fruto do distanciamento da representação sindical, uma vez que não foi verificada conexão entre o processo de gestão de competências e a ação do sindicato, posto que a área de Recursos Humanos, em geral, procura se antecipar às principais demandas dos trabalhadores (Amorim, 2010).

Os resultados dos grupos de foco revelam que a ação sindical não se apropriou ainda desse espaço de mobilização. Isso porque os sindicatos não trouxeram o debate sobre a gestão de competências para que os trabalhadores pudessem opinar sobre a definição de seus termos ou acerca dos incentivos à educação continuada, por exemplo. Em tese, a ocupação desse espaço de discussão poderia fortalecer a posição dos sindicatos na interlocução entre organização e trabalhadores. Dessa forma, os avanços incentivados nas relações de trabalho preconizados em nível macro por Antunes (2006) e em nível micro por Barbosa (2005) ainda não foram alcançados, refletindo as discussões pioneiras de Fischer e Fleury (1987). Paradoxalmente, o Estado brasileiro, que tanto regulamenta as relações de trabalho, continua ausente quanto à definição de uma política pública referente à indução das competências em geral.

Com tal leque de possibilidades, a verificação da presença da gestão por competências passa por uma constatação: ela faz parte do discurso gerencial nas organizações e, de fato, resulta em sua aplicação; de outro lado, esta aplicação normalmente é parcial em termos do conjunto das políticas e processos, deixando de lado a ação sindical.

\section{Posições Finais}

No caso brasileiro, as distintas práticas organizacionais vêm se ampliando diante de um cenário acirrado de competitividade entre as empresas, pressão do mercado internacional e menor regulação do Estado. Destaque-se ainda, nesse contexto, a fragilidade das instituições de proteção ao trabalhador, seja pelo caminho de politização das centrais sindicais, seja pela baixa efetividade do sindicato em ir além da discussão de reajustes salariais e pisos para os trabalhadores e assim reforçar sua legitimidade de representação. Quando do uso dos conceitos e instrumentos de gestão de pessoas a partir das 
competências, o mesmo acontece ao largo da interlocução sindical, reforçando assim, um dos achados de pesquisa.

A lacuna de articulação entre atores sociais que deveriam ser corresponsáveis pelo trabalho e pela renda e, em última instância, pelos trabalhadores, fica evidenciada. Revela ainda a ausência do Estado no sentido de posicionar-se, por meio da definição de políticas públicas capazes de estimular o emprego, e facilitar o acesso à formação de base e à capacitação para o mercado de trabalho. A pesquisa demonstrou a distância do sindicato em relação às práticas organizacionais, no sentido de gerar alternativas para proteção ao trabalhador, dado que a maioria das reivindicações continua centrada no binômio remuneração e estabilidade.

O percurso teórico para o desenvolvimento desta pesquisa demandou um levantamento bibliográfico que revela a maturidade da discussão do modelo de competências e suas características conceituais, técnicas (remuneração, carreira, desenvolvimento, atração, seleção e retenção) e das relações de trabalho no país (sindicatos, exercício e percepção de poder, regulação do Estado). Nessa trajetória, a produção acadêmica do processo organizacional chama a atenção, ainda que não leve em conta a interação com o trabalhador nas organizações. Se o conhecimento e a aprendizagem fazem parte dessa discussão, e têm como pressupostos a necessidade de comunicação e interação no processo de trabalho, é interessante verificar e confirmar potenciais contradições.

Outra questão que se apresenta pelos achados da pesquisa é que o estímulo à individualização das carreiras com a valorização do conhecimento contrapõe-se às exigências do trabalho coletivo. Nesse caso, estariam em foco aspectos comportamentais relacionados às condições e exigências de comprometimento dos trabalhadores em suas organizações. Há um papel para o sindicato neste contexto? E o Estado, como se posicionará?

Dada a histórica dificuldade de implantação de formas de gestão participativa no País, tais informações sugerem que os modelos de competências praticados pelas organizações em sua gestão de pessoas podem caracterizar-se por uma resistência à interlocução com os trabalhadores e suas formas de representação. Sendo esta hipótese a ser investigada, caberia ainda verificar se, entre os trabalhadores e seus representantes, também há resistências aos modelos de competências.

Em seus desdobramentos, esta pesquisa privilegia a percepção individual (trabalhadores) e coletiva (sindical) - da gestão por competências, e procura verificar se os trabalhadores e seus representantes estão aprendendo a lidar com ela. Espera-se que seja possível evidenciar as possíveis contradições no discurso empresarial (por exemplo: a favor do trabalho coletivo, mas não dando espaço para a representação coletiva) e sindical (provavelmente ainda preso ao mapa mental do fordismo/taylorismo), e como o Estado se posicionará para mediar tal conflito, uma das suas funções clássicas no sistema de relações de trabalho brasileiro. Por conseguinte, a perspectiva em dois lócus distintos de atuação sindical, Belo Horizonte e São Paulo, bem como em áreas de atuação tradicional das categorias profissionais, bancários e metalúrgicos, traz possibilidades de análises inovadoras e ainda pouco relacionadas sob o ponto de vista da gestão por competências, o papel do Estado, e em especial a atuação sindical.

Artigo recebido em 11.11.2011. Aprovado em 28.07.2012.

\section{Agradecimentos}

Os autores agradecem ao $\mathrm{CNPq}$ pelo apoio à pesquisa. 


\section{Nota}

${ }^{1}$ Este trabalho baseia-se em artigo apresentado no XXXV EnAnpad 2011 - Encontro da Associação Nacional de Pós-
Graduação e Pesquisa em Administração e premiado como o melhor trabalho da divisão acadêmica Gestão de Pessoas e
Relações de Trabalho e melhor trabalho EnAnpad 2011.

\section{Referências}

Alves-Mazzotti, A. J., \& Gewandsznajder, F. (1999). O método nas ciências naturais e sociais: pesquisa quantitativa e qualitativa. São Paulo: Pioneira.

Amorim, W. A. C. (2010). Negociações coletivas no Brasil: a hora dos aumentos reais? Informe FIPE, (361), 32-37.

Antunes, R. (2006). Riqueza e miséria do trabalho no Brasil. São Paulo: Boitempo.

Antunes, R., \& Alves, G. (2004). As mutações no mundo do trabalho na era da mundialização do capital. Educação e Sociedade, 25(87), 335-351. doi: 10.1590/S0101-73302004000200003

Barbosa, A. C. Q. (2002). Gestão de competências e o impacto na gestão de pessoas. Uma análise em grandes organizações de Minas Gerais (Relatório de Pesquisa/2002), Belo Horizonte, MG, Centro de Pós-Graduação e Pesquisas em Administração, Faculdade de Ciências Econômicas, Universidade Federal de Minas Gerais.

Barbosa, A. C. Q. (2005). Relações de trabalho e recursos humanos em busca de identidade [Edição Especial]. Revista de Administração de Empresas, 45, 121-126.

Barreto, L., Silva, M., Fischer, F., Dutra, J., Veloso, E., \& Amorim, A. (2010, maio). Gestão de pessoas: projetando desafios e tendências para 2015. Anais do Encontro da Divisão de Estudos Organizacionais da ANPAD, Florianópolis, SC, Brasil, 6.

Beck, U. (2010). Sociedade de risco: rumo a outra modernidade. São Paulo: Ed. 34.

Bitencourt, C. C., \& Barbosa, A. C. Q. (2010). Gestão de competências: articulando indivíduos, organizações e sociedade. In C. C. Bitencourt (Org.), Gestão contemporânea de pessoas (pp. 175-196). Porto Alegre: Bookman.

Bosalie, P., Brewster, C., \& Paauwe, J. (2009). In search of balance - managing the dualities of HRM: an overview of the issues. Personnel Review, 38(5), 461-471. doi: 10.1108/00483480910977992

Bresciani, L. P. (1997). Flexibilidade e reestruturação: o trabalho na encruzilhada. São Paulo em Perspectiva, 11(1), 88-97.

Brewster, C. (2007). Comparative HRM: European views and perspectives. International Journal of Human Resource Management, 18(5), 769-787. doi: 10.1080/09585190701248182

Bruyne, P. de. (1991). Dinâmica da pesquisa em ciências sociais. Rio de Janeiro: Francisco Alves.

Castells, M. (2003). A sociedade em rede. São Paulo: Paz e Terra.

Chesnais, F. (1996). A mundialização do capital. São Paulo: Xamã.

Clark, P. F. (2009). Building more effective unions. New York: ILR/Cornell Paperbacks.

Collis, J., \& Hussey, R. (2005). Pesquisa em administração. Porto Alegre: Bookman. 
Departamento Intersindical de Estatística e Estudos Socioeconômicos. (2010). Balanço das negociações dos reajustes salariais em 2010 (Estudos \& Pesquisas $\mathrm{N}^{\circ}$ 55). São Paulo, SP: Autor.

Dutra, J. S. (2004). (Org.). Competências: conceitos e instrumentos para a gestão de pessoas na empresa moderna. São Paulo: Atlas.

Fischer, A. L. (2001). O conceito de modelo de gestão de pessoas - modismo e realidade em gestão de recursos humanos nas empresas brasileiras. In J. S. Dutra (Org.), Gestão por competências: um modelo avançado para o gerenciamento de pessoas (pp. 9-22). São Paulo: Gente.

Fischer, R. M., \& Fleury, M. T. L. (1987). Processo e relações de trabalho no Brasil. São Paulo: Atlas.

Fleury, M. T. L., \& Sarsur, A. M. (2007). Nenhum a menos: desvendando conceitos sobre gestão por competências. In E. Davel, S. Vergara \& D. Ghardiri (Orgs.), Administração com arte (pp. 5979). São Paulo: Atlas.

Flick, U. (2004). Uma introdução à pesquisa qualitativa. Porto Alegre: Bookman.

Gorz, A. (1995). Saindo da sociedade do trabalho assalariado. São Paulo em Perspectiva, 9(3), 135144.

Guimarães, N. A., Hirata, H., \& Sugita, K. (2009). Trabalho flexível, empregos precários? Uma comparação Brasil, França, Japão. São Paulo: Edusp.

Ianni, O. (1997). Teorias da globalização. Rio de Janeiro: Civilização Brasileira.

Kaufman, B. E. (2010). The theoretical foundation of industrial relations and its implications for labor economics and human resource management. Industrial and Labor Relations Review, 64(1), 74108.

Krein, J. D., \& Gonçalves, J. R. (2006). Mudanças tecnológicas e seus impactos nas relações de trabalho e no sindicalismo do setor terciário (Relatório de Pesquisa/2006), Campinas, SP, Centro de Estudos Sindicais e Economia do Trabalho.

Kurz, R. (1997). Os últimos combates. Petrópolis: Vozes.

Leite, M. P. (2003). Trabalho e sociedade em transformação. Mudanças produtivas e atores sociais. São Paulo: Fundação Perseu Abramo.

Lüdke, M., \& André, M. E. D. A. (1986). Pesquisa em educação: abordagens qualitativas. São Paulo: EPU.

Morin, E. M. (2001). Os sentidos do trabalho. Revista de Administração de Empresas, 41(3), 8-19.

Nabuco, M. R., \& Carvalho, A. M., Neto (1999). Relações de trabalho contemporâneas. Belo Horizonte: Ed. PUC-Minas/IRT.

Pfeffer, J. (2007). Human resources from an organizational behavior perspective: some paradoxes explained. Journal of Economic Perspectives, 21(4) 115-134. doi: 10.1257/jep.21.4.115

Programa de Estudos em Gestão de Pessoas e Fundação Instituto de Administração. (2010). Melhores empresas para se trabalhar - Relatório de Benchmarking (p. 52). São Paulo: Autor.

Ramalho, J. R., \& Rodrigues, I. J. (2010). Sindicato, crise econômica e estratégias regionais novas dimensões da participação política no ABC Paulista. Cadernos CRH, 23(59), 339-351. 
Ribeiro, N. C. F., \& Santos, A. F. T. de (2008). Formação de trabalhadores no modelo da educação corporativa: homens ou máquinas? Educação Profissional: Ciência e Tecnologia, 3(1), 109118.

Rodrigues, L. M. (1979). Tendências futuras do sindicalismo brasileiro. Revista de Administração de Empresas, 19(4), 45-55.

Ruas, R. (2005). Gestão por competências: uma contribuição à estratégia das organizações. In R. Ruas, C. S. Antonello, \& L. H. Boff (Cols.), Aprendizagem organizacional e competências: os novos horizontes da gestão (pp. 34-55). Porto Alegre: Bookman.

Ruas, R., Ghedine, T., Dutra, J. S., Becker, G. V., \& Dias, G. B. (2005, setembro). O conceito de competência de A à Z - análise e revisão nas principais publicações nacionais entre $2000 \mathrm{e}$ 2004. Anais do Encontro Nacional da Associação Nacional de Pós-Graduação e Pesquisa em Administração, Brasília, DF, Brasil, 29.

Russo, G., Macedo-Soares, T., \& Villas, M. (2006, setembro). Importância da hierarquização das revistas científicas: resultados de uma investigação empírica no Brasil e proposta de um método de pesquisa bibliográfica. Anais do Encontro Nacional da Associação Nacional de PósGraduação e Pesquisa em Administração, Salvador, BA, Brasil, 30.

Santos, A. F. T. (2004, novembro). Teoria do capital intelectual e teoria do capital humano: estado, capital e trabalho na política educacional em dois momentos do processo de acumulação. Anais da Reunião Anual da ANPEd, Caxambu, MG, Brasil, 27.

Sarsur, A. M. (2010). Empresabilidade como uma "nova" gestão de recursos humanos. In C. C. Bitencourt (Org.), Gestão contemporânea de pessoas (pp. 261-284). Porto Alegre: Bookman.

Sarsur, A. M., Fischer, A. L., \& Amorim, W. A. C. de (2008). Gestão por competências: a (não) inserção dos sindicatos em sua implementação nas organizações. In J. S. Dutra, M. T. L. Fleury, \& R. Ruas (Orgs.), Competências: conceitos, métodos e experiências (pp. 253-283). São Paulo: Atlas.

Singer, P. (1996). Desemprego e exclusão social. São Paulo em Perspectiva, 10(1), 3-12.

Souza, S., \& Carvalho, A., Neto (2009). Reestruturação produtiva, trabalho e estratégias de desenvolvimento local à luz da teoria do novo regionalismo. Cadernos EBAPE.BR, 7(2), 275293. doi: 10.1590/S1679-39512009000200007

Veloso, J. P. R. (2002). O Brasil e a economia do conhecimento. Rio de Janeiro: José Olympio.

Vergara, S. C. (1998). Projetos e relatórios de pesquisa em administração. São Paulo: Atlas.

World Bank. (2011). Global economic prospect maintaining progress amid the turmoil (Volume 3). Washington, DC: Autor.

Zarifian, P. (2001). Objetivo competência: por uma nova lógica. São Paulo: Atlas. 